\section{(6) OPEN ACCESS}

\title{
Out of sight, out of mind? Removal of point-of-sale tobacco displays in Norway
}

\author{
Janne Scheffels, ${ }^{1}$ Randi Lavik ${ }^{2}$
}

${ }^{1}$ Norwegian Institute for Alcohol and Drug Research (SIRUS),

Oslo, Norway

${ }^{2}$ Norwegian Institute for Consumer Research (SIFO), Oslo, Norway

\section{Correspondence to}

Dr Janne Scheffels, Norwegian Institute for Alcohol and Drug Research (SIRUS), P0 Box 565 Sentrum, 0105 Oslo, Norway; js@sirus.no

Received 25 November 2011 Accepted 12 May 2012

Published Online First

7 June 2012

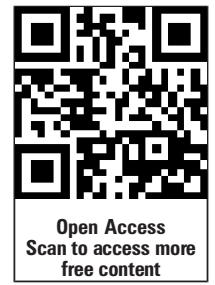

\section{ABSTRACT}

Aim To evaluate retailer's compliance and consumer's perceptions of and experiences with the point-of-sale (POS) tobacco display ban in Norway, implemented 1 January 2010.

Methods Retailer compliance was measured using audit surveys. Consumer's perceptions of the ban were assessed in three web surveys: one conducted before and two after implementation of the ban. The sample for each of these consisted of about 900 people aged 15-54 years and an extra sample of smokers and snus users. 10 focus group interviews with male and female daily, occasional and former smokers aged $16-50$ years $(\mathrm{N}=62)$ were also conducted, before and after implementation of the ban.

Results Immediately following implementation of the POS display ban, compliance was $97 \%$ for cigarettes and rolling tobacco and $98 \%$ for snus. Preimplementation, young people were tempted by tobacco products when seeing them in the shop more often than older people. Postimplementation, young people also more often found it difficult to choose brand. The POS tobacco display ban was supported by a majority of the population, and by one out of three daily smokers. The removal of POS tobacco displays was perceived as a barrier for young people's access to tobacco products, as affecting attachment to cigarette brands and as contributing to tobacco denormalisation.

Conclusions Retailer's compliance with the POS display ban in Norway was high, and the ban was well supported in the population. Consumers believed that the ban could contribute to preventing smoking initiation among young people and to some extent also support cessation efforts.

\section{INTRODUCTION}

Advertising has been shown to increase tobacco consumption, ${ }^{1}$ and tobacco smoking prevalence decreases when tobacco advertising is banned. ${ }^{2}$ A number of studies reviewing tobacco industry documents have revealed how the industry has used branding and package design as a strategy for complementing and extending the imagery created by advertising. ${ }^{3-5}$ When traditional forms of advertising are not allowed, one can assume that cigarette packages become particularly important as a means of communicating brand imagery. ${ }^{6}$ The point of purchase is a crucial arena for this. ${ }^{8}$ The importance of point-of-sale (POS) tobacco displays and the resources used for this purpose have been clearly expressed in tobacco industry documents. ${ }^{10}$ Research has demonstrated the importance of pack displays at the point of purchase for promoting tobacco initiation. A recent systematic review concluded that the evidence that POS advertising and displays increase susceptibility to smoking and uptake of smoking among youth is strong. ${ }^{11}$ In a retrospective study from Australia, $25 \%$ of smokers said that they purchased cigarettes at least sometimes on impulse as a result of seeing only cigarette displays and $33.9 \%$ of recent quitters said that they experienced an urge to buy cigarettes as a result of seeing the retail cigarette displays. ${ }^{12}$ Another Australian study based on immediate postpurchase interviews found that POS displays influenced nearly four times as many unplanned as planned purchases (47\% vs $12 \%, \mathrm{p}<0.01) .{ }^{13}$ Qualitative research with smokers in New Zealand has also indicated that tobacco retail displays can affect cessation attempts in a negative way. ${ }^{14}$

POS displays were banned first in Iceland (2001), then in Thailand (2005), in Canada (first in Saskatchewan in 2005), Ireland (2009) and most states of Australia (2009). In Ireland, a multifaceted evaluation of the implementation of the ban was undertaken, showing that compliance was very high and the new legislation was well supported. Recall of displays dropped significantly among adults and teenagers postlegislation, and there was also a drop in the proportion of teenagers thinking that many of their peers smoke, a finding that can be interpreted as a sign of denormalisation of smoking. ${ }^{15}$

In a ranking of the level of implementation of tobacco control policies in 30 European countries, Norway was ranked among the four countries with the highest level of restriction. ${ }^{16} \mathrm{~A}$ ban on all forms of tobacco advertising (including indirect advertising) was implemented in Norway in 1975. Regulations concerning packaging include health warnings (introduced in 1975), rules about declarations of product content on packages (1984) and restrictions on the use of innovative packaging to attract consumer's attention. On 1 January 2010, Norway removed POS displays of tobacco products through further provisions of the Norwegian Tobacco Act from 1973. The legislation mandated that tobacco products and related equipment (paper for rolling tobacco, etc) must be stored out of view from consumers. The ban applies also to imitations of tobacco products as well as vending machine cards that give customers access to take out tobacco products and related equipment. The Norwegian health authorities have stated that the aim of the initiative was to prevent youth smoking initiation and to support cessation efforts. ${ }^{17}$ In this study, we report findings from the evaluation of the removal of POS tobacco displays in Norway. Results on retailer compliance, consumers' experiences with buying tobacco when seeing products displayed in shops before the ban was implemented 
and support for and expectations towards the ban after implementation are presented.

\section{METHODS}

Data on the process of implementation were collected from retail audit surveys. Consumers' perceptions of and experiences with the ban were assessed by web surveys carried out before and after the display ban was implemented and by focus group interviews with consumers. All market research agencies involved in the collection of data presented in this paper (Nielsen Norway, TNS Gallup and Synovate AS/Ipsos MMI) abide by an ethical code of conduct, as stated in the principles of the international market research trade organisation ESOMAR.

\section{Retail audit surveys}

In January 2010, a representative sample of 351 grocery shops, randomly selected from a comprehensive list of 4000 grocery shops, were visited by observers from Nielsen Norway. The observers registered whether the shops had implemented a system to ensure that tobacco products were kept out of sight, and if so, what kind of system. Nielsen Norway does regular observation studies in grocery shops for clients; questions about the POS display were included in the observers protocol for the purpose of this study. The registration was done by a standardised questionnaire developed by the authors of this study.

\section{Web surveys}

Three web (electronic) surveys were carried out by TNS Gallup: one in November 2009 ( $N=941$ ) before the ban and two after the ban, one in January 2010 (to identify immediate effects of the ban, $\mathrm{N}=909$ ) and another in November 2010 (to identify more long-term effects, $\mathrm{N}=904$ ). The respondents were randomly drawn from an internet panel consisting of 60000 respondents. The upper age limit was set to 54 years, given that the main target group for this intervention was young smokers and snus users. Additional samples $(\mathrm{N}=309,352,316)$ were drawn at all three points in time to get a sufficient sample of smokers/snus users for statistical analysis. Recruiting from a panel provided the opportunity to contact potential respondents by email. The advantage of a web solution is that the respondents have great flexibility when answering the questionnaire compared with a computer-assisted telephone interviewing solution. Ninety-four per cent of the Norwegians in the age of 15-60 years have access to a computer. The respondents received incentives to participate in the form of 'credit points' (usually one point per minute it takes to complete the survey). The credit points can be exchanged into gifts or they can be donated to charitable purposes. In all the interviews, questions were asked about tobacco use, attitudes towards tobacco use and support for the ban (table 1).

\section{Statistical analysis}

For the analysis of the total population, the data were weighted to represent the target Norwegian population in terms of age (15-54 years) and gender. The differences between the age and gender distribution and the distribution of the same variables in the population were very small, but in order to ensure accuracy we still chose to weight the data. ${ }^{17}$ The data were not weighted for the analyses of smokers/snus users separately since the true age and gender of the total population of smokers/snus users was not known. Smokers/snus users from the population sample and the extra sample of smokers/snus users showed no differences according to age and gender distribution. $\chi^{2}$ tests were used to determine the statistical significance of changes in response to each question before and after the implementation of the new legislation. $\chi^{2}$ tests were also used to determine differences between age groups. In order to obtain a clearer overview of the findings, we have chosen not to show the distributions of all values for some questions, but summarised some of the values and presented them as proportion percentages. The only case where the 'don't know' value was higher than 1\%-2\% was the question about attitudes towards the ban. The 'don't know' value was thus included in the analysis for this variable, while it was excluded from the analysis for all other variables.

\section{The focus group study}

Questions about the forthcoming display ban were included in five focus group interviews (32 participants) about cigarette packaging in November 2009, 2 months before the POS display ban was implemented. Five more focus group interviews with

Table 1 Questions about the tobacco ban in the web surveys, respondents $15-54$ years old

\begin{tabular}{|c|c|c|}
\hline Questions & Responses & Timing \\
\hline \multicolumn{3}{|l|}{ Smokers/snus users } \\
\hline $\begin{array}{l}\text { Do you ever get tempted to buy tobacco or snus } \\
\text { when you see the products at the point of sale? }\end{array}$ & $\begin{array}{l}\text { 1. Yes, often } \\
\text { 2. Yes, sometimes } \\
\text { 3. No, never }\end{array}$ & November 2009 \\
\hline $\begin{array}{l}\text { On } 1 \text { January 2010, a ban of point-of-sale displays } \\
\text { of all tobacco products was implemented. How strongly } \\
\text { do you agree or disagree with the following statement: } \\
\text { 'The ban has made it more difficult for me to choose brand' }\end{array}$ & $\begin{array}{l}\text { 1. Totally agree } \\
\text { 2. Partly agree } \\
\text { 3. Partly disagree } \\
\text { 4. Totally disagree } \\
\text { 5. Don't know* }\end{array}$ & November 2010 \\
\hline $\begin{array}{l}\text { On } 1 \text { January 2010, a ban of point-of-sale displays of all } \\
\text { tobacco products was implemented. How strongly do you } \\
\text { agree or disagree with the following statement: 'The ban } \\
\text { has made it more difficult for me to buy tobacco products' }\end{array}$ & $\begin{array}{l}\text { 1. Totally agree/ } \\
\text { 2. Partly agree/ } \\
\text { 3. Partly disagree/ } \\
\text { 4. Totally disagree/ } \\
\text { 5. Don't know* }\end{array}$ & November 2010 \\
\hline \multicolumn{3}{|l|}{ Total population + extra sample of smokers/snus users } \\
\hline $\begin{array}{l}\text { On the } 1 \text { January } 2010 \text {, a ban of point-of-sale displays of all } \\
\text { tobacco products will be implemented. (On } 1 \text { January } 2010 \text {, } \\
\text { a ban of point-of-sale displays of all tobacco products was } \\
\text { implemented). Are you in favour or against such a ban? }\end{array}$ & $\begin{array}{l}\text { 1. In favour } \\
\text { 2. Against } \\
\text { 3. Don't know }\end{array}$ & $\begin{array}{l}\text { November } 2009 \\
\text { January } 2010 \\
\text { November } 2010\end{array}$ \\
\hline $\begin{array}{l}\text { Do you think the ban will make it easier to quit smoking or } \\
\text { using snus? Do you think the ban will make it more difficult } \\
\text { to start smoking or using snus? }\end{array}$ & $\begin{array}{l}\text { 1. Yes } \\
\text { 2. Maybe } \\
\text { 3. No } \\
\text { 4. Don't know* }\end{array}$ & $\begin{array}{l}\text { November } 2009 \\
\text { January } 2010 \\
\text { November } 2010\end{array}$ \\
\hline
\end{tabular}

*Don't know excluded from the analysis. 
a total of 30 participants were carried out in April 2010, 3 months after implementation. In both studies, interviewees were recruited to promote diversity as regards gender, age and smoking status: young and adult daily smokers (DS 16-19, DS 18-21, DS 20-29, DS 30-50), young (OS 18-21) occasional smokers and young adult (XS 20-29) and adult ex-smokers (XS 30-50) participated. All groups were gender mixed. Group size varied from four to eight persons, and the interviews lasted 90-120 min. Interviewees were recruited by Synovate AS/Ipsos MMI, mostly from their list of panel members, and the interviews were led by a trained moderator. A semistructured interview guide was used to investigate how interviewees perceived the significance of the POS display ban for themselves and for others. All interviews were video recorded and transcribed and analysed using NVivo8 software package for qualitative analysis. The transcripts were read and discussed between both authors. Interviewees received a gift voucher of NOK 500 to compensate for their participation in the study.

\section{RESULTS}

\section{Retail audit surveys}

The products were kept out of sight in different ways: most often within a closed cabinet, behind shelves with flaps or in a 'Vensafe' system (figure 1). Vensafe is a technical solution to protect valuable products from being stolen. The customers have to buy a card kept at the counter in order to get the products out of the cabinet. The new regulation forbids showing any image or logo of the package on the cards. Snus is stored either in special fridges near the checkout counter or in a Vensafe system. Before the display ban was implemented, the doors of the snus fridges were always transparent so that customers could see the packages. After 1 January, the doors of the fridges had to be non-transparent.

At the end of January 2010, the retail audit found $92 \%$ compliance with the requirement to store tobacco products out of view. Only $3 \%$ of the shops had not implemented any measure to store cigarettes, rolling tobacco and smoking equipment out of view. In $5 \%$ of the samples, the retailers had installed Vensafe, but the cards showed logos. The retailers explained that this was because delivery of new cards had been delayed and they claimed that correct cards would be used as soon as possible. The retail audit found 98\% compliance with the requirement to conceal snus products. Fifty-seven per cent of the shops had put signs in bold black lettering: TOBACCO/ CIGARETTES on their tobacco storage system. Twenty-nine per cent of the shops had visible signs informing about the age limit of 18 years to purchase tobacco products.

\section{Web surveys}

In the web survey performed before the implementation of the new regulation, $26 \%$ of smokers/snus users replied that they were tempted to buy tobacco when seeing such products displayed in the shop. Younger respondents more often reported this than older: $12 \%$ of the youngest said that they were often tempted to buy after seeing tobacco displays in shops compared with $2 \%$ of the other age groups $(p<0.001 \mathrm{df}=1)$. After the ban was implemented, smokers and snus users were asked whether they felt the ban had made it more difficult for them to choose brand and to buy tobacco products. Twenty per cent of the respondents said that they felt the ban had made it more difficult to buy tobacco products, while $32 \%$ said that it had made it more difficult to choose a brand. There were no significant differences between the different age groups as to whether they regarded that the ban had made it more difficult to buy tobacco products. However, the younger respondents were more likely than the oldest respondents to say that the ban had made it more difficult to choose a brand: 35\% of 15-24-year-olds reported this experience: compared with $23 \%$ among smokers and snus users between 45 and 54 years $(\mathrm{p}=0.035 \mathrm{df}=1)$ (table 2$)$.

Support for the removal of the POS tobacco display ban was strongly related to smoking status: more than $70 \%$ of the nonsmokers/non-snus users were in favour of the ban, while $50 \%$ of the occasional smokers and about $30 \%$ of the daily smokers. Support for the ban was more prevalent among daily snus users than among daily smokers at all three points of measurement (table 3). All three surveys showed that it was more usual to expect the ban would come to be useful for preventing the uptake of tobacco use compared with stimulating smoking cessation or quitting snus use. Daily smokers reported less faith in the effect of the ban compared with non-smokers in all three surveys. Still, around $50 \%$ of daily smokers and $60 \%$ of occasional smokers believed that the ban would be effective in preventing smoking or snus use initiation. Snus use had less influence on expectations of the effect of the display ban than smoking habits (table 3 ).

\section{Focus groups with consumers}

In order to create a discussion context, questions about cigarette packages as expressions of brand image were asked at the beginning of all the interviews. Clear images of brands and user identities associated with these were narrated in all groups. The agreement of the stories of brand images between interviewees and between groups was substantial. Brand images were described as the basis for differentiation between and identification with brands, and the images were often connected to basic social categories, such as gender, age or social class, or along an urban/rural dimension. For example, Marlboro red was associated with masculinity, Prince (brand of Danish origin) with low social class and Petteroes (brand of Norwegian origin) with rurality. Different elements in the package design, such as colours, fonts and emblems were described as underlining brand images. The younger participants sketched out narratives about brand image most creatively, indicating perhaps that this
Figure 1 Examples of systems used to conceal tobacco products.
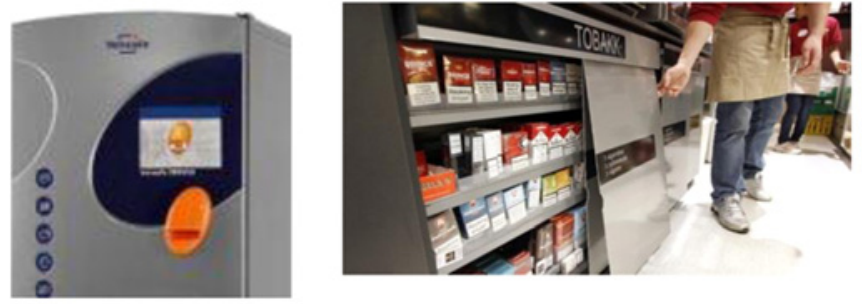

Cabinets with doors

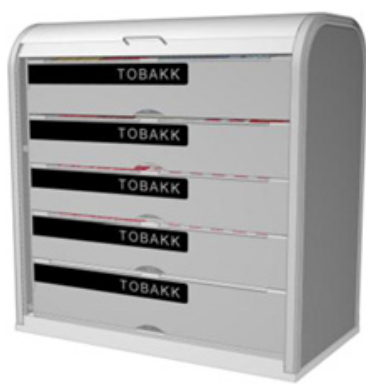

Shelves with flaps 
Table 2 Point-of-sale assessment by age: daily and occasional smokers/snus users

\begin{tabular}{lcccccc}
\hline & $\mathbf{1 5}-\mathbf{2 4}$ years & $\mathbf{2 5 - 3 4}$ years & $\mathbf{3 5 - 4 4}$ years & $\mathbf{4 5 - 5 4}$ years & Total & $\mathbf{p}$ Value \\
\hline November 2009: Do you ever get tempted to buy tobacco or snus when you see the products at the point of sale? \\
Yes, often & $12 \%$ & $2 \%$ & $2 \%$ & $2 \%$ & $4 \%$ & $\mathrm{p}<0.001$ (df=6) \\
Yes, sometimes & $34 \%$ & $27 \%$ & $17 \%$ & $10 \%$ & $22 \%$ & \\
No, never & $55 \%$ & $71 \%$ & $81 \%$ & $89 \%$ & $75 \%$ & \\
N & 130 & 208 & 190 & 174 & 707 & \\
November 2010: statement: 'The new ban has made it more difficult for me to choose brand' & & \\
Agree (totally or partly) & $35 \%$ & $37 \%$ & $30 \%$ & $23 \%$ & $31 \%$ & $\mathrm{p}=0.032$ (df=3) \\
Disagree (totally or partly) & $65 \%$ & $64 \%$ & $70 \%$ & $77 \%$ & $69 \%$ & \\
N & 100 & 219 & 203 & 153 & 675 & \\
November 2010: statement: 'The new ban has made it more difficult for me to buy tobacco products' & \\
Agree (totally or partly) & $22 \%$ & $19 \%$ & $20 \%$ & $21 \%$ & $20 \%$ & $\mathrm{NS}, \mathrm{p}=0.925$ \\
Disagree (totally or partly) & $78 \%$ & $81 \%$ & $80 \%$ & $79 \%$ & $80 \%$ & (df=3) \\
N & 102 & 220 & 202 & 154 & 678 & \\
\hline
\end{tabular}

Values are expressed in percentage.

NS, not significant.

dimension was more important for their relationship to smoking than it was for the older interviewees.

In both the pre- and postimplementation interviews, daily smokers described their way of buying cigarettes as very habitual, like buying bread or milk. In this context, many were critical to the forthcoming ban before implementation: 'I do not see the point, cigarettes are not something you buy on impulse, you go out to get your cigarettes' (M, DS 16-19). Some occasional and former smokers expressed similar expectations, while others were positive: 'It's like candy. If you don't see it then you don't get the urge for it' (W, XS 20-29).

After implementation, most daily smokers said that they did not feel markedly affected by the POS display ban. However, some said that they felt the ban had made it more inconvenient to buy cigarettes because they could no longer see the packages and had to ask the checkout staff for assistance. Among ex- and occasional smokers, the assessment of the ban after implementation was again a lot more diverse. Some of the occasional smokers expressed scepticism in line with the daily smokers, while others felt that the ban could have led to them being 'triggered' to buy cigarettes less often: 'I know that I respond to the colours on the packs, so when I do not see them anymore I think I could get less tempted sometimes' (W, OS 18-21). These evaluations were related to how they explained their way of buying cigarettes: often on impulse. The ex-smokers were also divided as to whether they believed that the ban could support

Table 3 Support for and expectations of the ban pre- and postlegislation by smoking and snus use status

\begin{tabular}{|c|c|c|c|c|}
\hline & $\begin{array}{l}\text { Prelegislation } \\
\text { (November 2010) }\end{array}$ & $\begin{array}{l}\text { Postlegislation } \\
\text { (January 2010) }\end{array}$ & $\begin{array}{l}\text { Postlegislation } \\
\text { (November 2010) }\end{array}$ & p Value \\
\hline \multicolumn{5}{|c|}{ In favour of the ban (against and don't know omitted in the table) } \\
\hline Daily smokers & $29(355)$ & $30(373)$ & $32(319)$ & $N S, p=0.659(d f=2)$ \\
\hline Occasional smokers & $58(207)$ & $51(234)$ & $49(226)$ & $N S, p=0.139(d f=2)$ \\
\hline $\mathrm{p}$ Value & $\mathrm{p}<0.001(\mathrm{df}=1)$ & $\mathrm{p}<0.001(\mathrm{df}=1)$ & $\mathrm{p}<0.001(\mathrm{df}=1)$ & \\
\hline Daily snus users & $51(165)$ & $43(170)$ & $48(174)$ & $N S, p=0.399(d f=2)$ \\
\hline Occasional snus users & $51(150)$ & $53(149)$ & $47(142)$ & $N S, p=0.606(d f=2)$ \\
\hline $\mathrm{p}$ Value & $N S, p=0.97(d f=1)$ & $N S, p=0.072(d f=1)$ & $N S, p=0.927(d f=1)$ & \\
\hline Non-smokers and non-users of snus combined & $77(552)$ & $72(511)$ & $74(532)$ & $N S, p=0.150(d f=2)$ \\
\hline \multicolumn{5}{|c|}{ Expects the ban will make it easier to quit smoking or using snus (does not expect and don't know omitted in the table) } \\
\hline Daily smokers & $27(339)$ & $24(364)$ & $21(308)$ & NS, $0.141(\mathrm{df}=2)$ \\
\hline Occasional smokers & 55 (199) & 46 (229) & $39(215)$ & $0.004(\mathrm{df}=2)$ \\
\hline $\mathrm{p}$ Value & $p<0.001(d f=1)$ & $\mathrm{p}<0.001(\mathrm{df}=1)$ & $\mathrm{p}<0.001(\mathrm{df}=1)$ & \\
\hline Non-smokers & $61(602)$ & $55(556)$ & $58(582)$ & $\mathrm{NS}, \mathrm{p}=0.086(\mathrm{df}=2)$ \\
\hline Daily snus users & $39(158)$ & $33(164)$ & $27(169)$ & \\
\hline Occasional snus users & $50(146)$ & $47(146)$ & $41(136)$ & $\mathrm{p}=0.052(\mathrm{df}=21) \mathrm{NS}, \mathrm{p}=0.318(\mathrm{df}=2)$ \\
\hline $\mathrm{p}$ Value & $\mathrm{NS}, \mathrm{p}=0.059(\mathrm{df}=1)$ & $p=0.010(d f=1)$ & $p=0.007(d f=1)$ & \\
\hline Non-users of snus & $57(740)$ & $49(691)$ & $51(696)$ & $\mathrm{p}=0.006(\mathrm{df}=2)$ \\
\hline \multicolumn{5}{|c|}{ Believes the ban will make it more difficult to start smoking or using snus (does not expect and don't know omitted in the table) } \\
\hline Daily smokers & $48(335)$ & $50(362)$ & $52(302)$ & $N S, p=0.663(d f=2)$ \\
\hline Occasional smokers & $61(197)$ & $62(223)$ & $57(218)$ & $\mathrm{NS}, \mathrm{p}=0.528(\mathrm{df}=2)$ \\
\hline $\mathrm{p}$ Value & $\mathrm{p}=0.003(\mathrm{df}=1)$ & $p=0.003(d f=1)$ & $\mathrm{NS}, \mathrm{p}=0.138(\mathrm{df}=1)$ & \\
\hline Non-smokers & $66(599)$ & $62(558)$ & $64(573)$ & $\mathrm{NS}, \mathrm{p}=0.264(\mathrm{df}=2)$ \\
\hline Daily snus users & $52(156)$ & $52(164)$ & $60(163)$ & $N S, p=0.252(d f=2)$ \\
\hline Occasional snus users & $58(145)$ & $60(144)$ & $58(139)$ & $N S, p=0.898(d f=2)$ \\
\hline $\mathrm{p}$ Value & $N S, p=0.295(d f=1)$ & $N S, p=0.159(d f=1)$ & $N S, p=0.074(d f=1)$ & \\
\hline Non-users of snus & $64(734)$ & $60(697)$ & $60(688)$ & $N S, p=0.180(d f=2)$ \\
\hline
\end{tabular}

Values are expressed in \% (N).

NS, not significant. 
their efforts to remain smoke-free. Some said that they believed the ban could reduce impulses to buy tobacco, others talked about the impact of the ban in a more normative sense: 'I agree with this, I think it is OK that they restrict it even more. Actually, I do not think I would have managed to quit had it not been for this... mass suggestion in society, I feel supported by it' (W, XS 30-50). Others were more negative and related this to their belief that it was not in the shopping situation that they got an urge to smoke: '...but in the situations where I always used to smoke before, like at parties, or when I am frustrated' (W, XS 30-50).

While the interviewees had diverse opinions about how the ban affected themselves, a majority of respondents in all groups expressed a belief in and support for the ban as a means of preventing smoking initiation. The reasons stated were, for example, that the display ban made it more difficult to choose brand, and the cabinets were seen as an additional barrier that could make it more unpleasant or scary for minors to buy cigarettes: 'If you just see a grey sign with letters on, it's not as cool as when you see the colours and images. You can't see which pack is cooler either. And I think it could be more frightening for young people. Either you have to ask the cashier or you have to fumble with one of those machines' (W, OS 18-21). Covering up cigarettes was also seen as making cigarettes less visible in daily life. Sometimes this was framed in a very concrete way: 'It could be that those who never smoked before...when they don't see it they won't think about that they want to try...in that sense it will be different from when we started' (W, DS 18-21). Other times this point came up in relation to other issues, for example, related to how the ban might lead to less attachment to brands: 'I think this is smart for young people. I remember we used to study the packs in the shops and discuss what to buy when I was that age' (W, OS 20-29). 'When young people no longer see the packs, except at home maybe, perhaps they will not have the associations to them that we had' (W, XS 30-50). Also, many interviewees said that they believed the POS display ban could contribute to a strong trend or 'fashion' of non-smoking, in particular among young people: 'I guess this will strengthen a trend that is already there, that smoking is not cool any more' (W, XS 30-50). In all groups, but particularly in the groups with the oldest and most experienced current and former smokers, statements like this were blended with a discussion about denormalisation in a more normative sense: 'The cabinets underline the fact that smoking is not good for you. No other products you buy in the shops are hidden in this way' (M, OS 18-21). 'I get the feeling, when cigarettes are hidden like this, that I am doing something illegal when I buy cigarettes' (W, DS 30-50). While the adult smokers were often critical to this process for themselves, they talked positively about how denormalisation can contribute to preventing smoking initiation among future generations.

\section{DISCUSSION AND CONCLUSIONS}

The evaluation of the POS tobacco display ban in Norway showed that retailer's compliance with the POS tobacco display ban was high, shortly after 1 January. Removals of POS display bans are introduced primarily to protect children and youth from the advertising effect of seeing packages in stores. Research has shown that familiarity with and preference for particular brands increase probability for smoking initiation ${ }^{18}$ and that brand preference plays a role in smoking maintenance and intensity. ${ }^{19}$ The stories about brand differentiation and identification that came forward in the focus group interviews undertaken as part of this evaluation study clearly reflected the influence that tobacco imagery exerts on young people. They also revealed how displays of cigarette packages at the POS uphold brand visibility and contribute to positioning tobacco as an ordinary commodity. In the web survey, we found that young people more often than older reported that they were tempted to buy tobacco when seeing products in shops before the ban was implemented. The young also most often reported that they experienced the ban as making it more difficult to choose brand in the post-ban surveys. Seen together, these findings indicate that the POS tobacco display ban can be useful in disturbing the processes that branding works through to make smoking attractive, ${ }^{20}$ particularly among youth.

The display ban was in general well supported in the Norwegian population. In contrast to findings from the evaluation of the ban on smoking in bars and restaurants that was implemented in Norway in $2004^{21}$ and findings from the evaluation of the same policy in Ireland before this, ${ }^{22}$ our data did not reveal any significant changes in support from before to after implementation. However, we did in line with the evaluation of smoke-free hospitality venues find that support was markedly stronger among non-smokers than among smokers, and among occasional smokers compared with daily smokers. Interestingly, the evaluation of the ban on smoking in bars and restaurants in Norway showed that support increased more among smokers compared with non-smokers over time. ${ }^{21}$ Against this background, further research to evaluate the development in support for the POS tobacco display ban could be interesting.

The survey data showed that occasional smokers were more positive towards the effect of the ban than daily smokers. This difference was evident also in the focus group data. The qualitative study also provided some indications as to how this finding may be understood. Perhaps could removal of tobacco displays be experienced as more personally relevant for this group, who more often buy their products on impulse? Similarly, the analysis of both data sets indicated that a majority of daily smokers, in spite of their disbelief in the effect of the POS tobacco display ban as stimulation of cessation attempts, did think that POS display could be an effective means to prevent initiation of tobacco use. The focus group data again provide some context for interpretation: respondents talked about how the POS display ban makes cigarettes less accessible to adolescents and also contributes to denormalisation of smoking. However, it is well known how people generally tend to believe that others are more likely to be affected by persuasive communication than themselves ${ }^{23}$ : some of the explanation to why daily smokers believe youth are more likely to be affected by the display ban than they are, could perhaps also be related to this phenomenon.

The removal of POS tobacco displays in Norway is an amendment of the tobacco-advertising ban that was implemented in 1975. Tellingly, the administrative regulation following the 1973 Tobacco Act explicitly states displays of tobacco at POS as an exception from the advertising ban. ${ }^{24}$ As we write this, the removal of POS tobacco displays in Norway is being challenged by a lawsuit from Phillip Morris, who believes that their interests may be at risk. Indeed, the strength of the resistance from the tobacco industry has also before this been a valid barometer of the effect that this measure is expected to have on their sales.

In conclusion, the experience from Norway supports previous evidence from Ireland that implementation of a tobacco retail display ban is feasible on a national scale. Also in Norway, the POS display ban was generally popular, supported also by one 


\section{What this paper adds}

This paper reports findings from the evaluation of the implementation of POS tobacco display ban in Norway, implemented on 1 January 2010.

- Compliance with the law was very high, and the law was well supported.

- The removal of POS displays of tobacco was perceived as a barrier for young people's and children's access to tobacco products. There were also signs that the display ban could affect attachment to tobacco brands and contribute to denormalisation of smoking.

third of daily smokers. Based on the evaluation from consumers, the display ban seems to be contributing to a more supportive environment for non-smoking, in particular among young people. These findings indicate that the removal of the POS tobacco displays in Norway, together with other tobacco control policies implemented over the last decades, can contribute to reduce tobacco use.

Contributors The authors developed the study in cooperation. RL performed all the statistical analysis and JS the qualitative data analysis.

Funding The study was financed by the Norwegian Directorate of Health and Social Affairs.

Competing interests None.

Provenance and peer review Not commissioned; externally peer reviewed.

Open Access This is an Open Access article distributed in accordance with the Creative Commons Attribution Non Commercial (CC BY-NC 3.0) license, which permits others to distribute, remix, adapt, build upon this work non-commercially, and license their derivative works on different terms, provided the original work is properly cited and the use is non-commercial. See: http://creativecommons.org/ licenses/by-nc/3.0/

\section{REFERENCES}

1. Saffer $\mathbf{H}$, Chaloupka $F$. The effect of tobacco advertising on tobacco consumption. $J$ Health Econ 2000;19:1117-37.

2. MacFadyen L, Hastings G, Macintosh AM. Cross sectional study of young people's awareness of and involvement with tobacco marketing. BMJ 2001:322:513-17.
3. Wayne GF, Connolly G. How cigarette design can affect youth initiation into smoking: Camel cigarettes 1983-93. Tob Control 2002;11:i32-9.

4. DiFranza JR, Clark DM, Pollay RW. Cigarette package design: opportunities for disease prevention. Tob Induc Dis 2002:1:97-109.

5. Wakefield M, Morley C, Horan JK, et al. The cigarette pack as an image: new evidence from tobacco industry documents. Tob Control 2002;11:73-80.

6. Freeman B, Chapman S, Rimmer M. The case for the plain packaging of tobacco products. Addiction 2008;103:580-90.

7. Wakefield MA, Terry-McElrath YM, Chaloupka FJ, et al. Tobacco Industry Marketing at Point of Purchase After the 1998 MSA Billboard Advertising Ban. Am J Public Health 2002;92:937-40.

8. Dewhirst T. POP goes the power wall? Taking aim at tobacco promotional strategies utilized at retail. Tob Control 2004;13:209-10.

9. Lavack AM, Toth G. Tobacco point-of-purchase promotion: examining tobacco industry documents. Tob Control 2006;15:377-84.

10. Pollay RW. More than meets the eye: on the importance of cigarette retail merchandising. Tob Control 2007:16:270-4.

11. Paynter J, Edwards R. The impact of tobacco promotion at the point of sale: a systematic review. Nicotine Tob Res 2009;11:25-35.

12. Wakefield M, Germain D, Henriksen L. The effect of retail cigarette pack displays on impulse purchase. Addiction 2008;103:322-8.

13. Carter $\mathbf{0}$, Mills B, Donovan R. The effect of retail cigarette pack displays on unplanned purchases: results from immediate post-purchase interviews. Tob Control 2009;18:218-21

14. Hoek J, Gifford H, Pirikahu G, et al. How do tobacco retail displays affect cessation attempts? Findings from a qualitative study. Tob Control 2010;19:334-7.

15. McNeill A, Lewis S, Quinn C, et al. Evaluation of the removal of point-of-sale tobacco displays in Ireland. Tob Control 2011:20:137-43.

16. Joosens L, Raw M. The tobacco control scale: a new scale to measure country activity. Tob Control 2006;15:247-53.

17. Lavik R, Scheffels J. Evaluering av forbud mot synlig oppstilling av tobakksvarer. Oslo: Statens institutt for forbruksforskning (SIFO)/Statens institutt for rusmiddelforskning (SIRUS). Fagrapport nr 2/2011.

18. Biener L, Siegel M. Tobacco marketing and adolescent smoking: more support for a causal inference. Am J Pub Health 2009;90:407-11.

19. Volk RJ, Edwards DW, Lewis RA, et al. Smoking and preference for brand of cigarettes among adolescents. J Subst Abuse 1996;8:347-59.

20. Hulberg J. Integrating corporate branding and sociological paradigms: a literature study. Journal of Brand Management 2006:14:60-73.

21. Aaro LE, Lund KE, Vedoy TF, et al. Evaluering av myndighetenes samlede innsats for å forebygge tobakksrelaterte sykdommer i perioden 2003 til 2007. Oslo: SIRUS Rapport, 2009.

22. Fong GT, Hyland A, Borland $R$, et al. Reductions in tobacco smoke pollution and increases in support for smoke-free public places following the implementation of comprehensive smoke-free workplace legislation in the Republic of Ireland: findings from the ITC Ireland/UK Survey. Tobacco Control 2006:iii51-iiii.

23. Davidson PW. The third person effect in communication. Public Opin $Q$ 1983:47:1-15

24. Lund KE, Rise J. Kunnskapsgrunnlag for forslaget om et forbud mot synlig oppstilling av tobakksvarer. SIRUS skrifter $\mathrm{nr}$ 1/2008. Oslo: Statens institutt for rusmiddelforskning, 2008. 